\title{
Odontogenic cysts: Demographic profile in a Brazilian population over a 38-year period
}

\author{
Lélia-Batista de Souza ${ }^{1}$, Manuel-Antonio Gordón-Núñez ${ }^{2}$, Cassiano-Francisco-Weege Nonaka ${ }^{3}$, Marcell- \\ Costa de Medeiros ${ }^{4}$, Tabita-Fernandes Torres ${ }^{4}$, Gustavo-Barbalho-Guedes Emiliano ${ }^{5}$
}

\author{
${ }^{1}$ DDS, PhD, Professor, Department of Oral Pathology, Federal University of Rio Grande do Norte -UFRN, Natal, RN, Brazil \\ ${ }^{2}$ DDS, PhD, Post-Doctorate student, Programa de Becas Postdoctorales 2005-2010, IFARHU/SENACYT, Panamá / UFRN, Brazil \\ ${ }^{3}$ DDS, MSc, Post-graduate student, Department of Oral Pathology, Federal University of Rio Grande do Norte - UFRN, Natal, \\ RN, Brazil \\ ${ }^{4}$ Undergraduate student, School of Dentistry, PIBIC/ CNPq, Federal University of Rio Grande do Norte - UFRN, Natal, RN, Brazil \\ ${ }^{5}$ DDS, Specialist in Forensic Dentistry, School of Dentistry, University of the State of Rio Grande do Norte - UERN, Caicó, RN, \\ Brazil
}

Correspondence: Avenida Senador Salgado Filho, 1787

Lagoa Nova - Natal - RN

Brasil CEP: 59056-000

leliabsouza@gmail.com

Received: 23/06/2009 Accepted: 28/11/2009
Souza LB, Gordón-Núñez MA, Nonaka CW, Medeiros MC, Torres TF, Emiliano GBG. Odontogenic cysts: Demographic profile in a Brazilian population over a 38-year period. Med Oral Patol Oral Cir Bucal. 2010 Jul 1;15 (4):e583-90.

http://www.medicinaoral.com/medoralfree $01 / \mathrm{v} 15 \mathrm{i} 4 /$ medoralv15i4p583.pdf

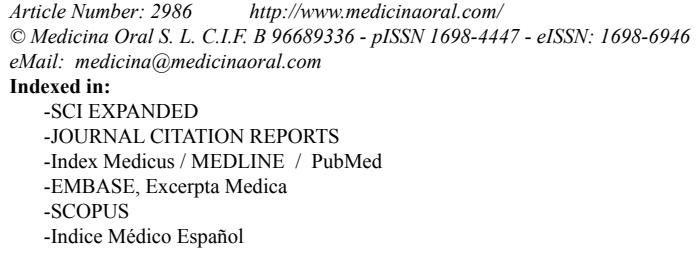

\begin{abstract}
Objective: To determine the distribution of odontogenic cysts diagnosed histologically over a period of 38 years in a Brazilian population according to age, gender and site affected and to compare these data with previously reported studies from other countries.

Study design: A total of 1019 cases of odontogenic cysts diagnosed between 1970 and 2007 were studied. Clinical features obtained from the patient records and microscope slides were reviewed according to the 1992 World Health Organization classification.

Results: The mean age was 31.0 years, and there was a predominance of females. The most frequent odontogenic cysts were radicular cysts (61.4\%), followed by dentigerous cysts $(20.1 \%)$ and odontogenic keratocysts $(6.4 \%)$. Radicular cysts were more frequent in females $(62.0 \%)$, and the maxillary teeth were the site most commonly involved (63.05\%). The peak incidence of dentigerous cysts occurred in the second decade of life, with the posterior region of the mandible being the site most affected (46.3\%), followed by the anterior region of the maxilla (27.8\%). Odontogenic keratocysts showed a peak incidence between the third and fourth decades of life and predominance among females. The posterior region of the mandible was the site most frequently affected $(65.6 \%)$.

Conclusion: The present results showed a similar frequency of odontogenic cysts in this Brazilian population and other populations around the world, with inflammatory cysts being identified as the most frequent odontogenic cyst. Radicular cysts, dentigerous cysts, and odontogenic keratocysts are the most common cystic lesions, accounting for $87.9 \%$ of all odontogenic cysts.
\end{abstract}

Key words: Odontogenic cyst, radicular cyst, dentigerous cyst, keratocyst. 


\section{Introduction}

Odontogenic cysts (OCs) are one of the most common osseous-destructive lesions affecting the jaws (1). These cysts arise from the epithelial components of the odontogenic apparatus or its remnants $(2,3)$ that lie entrapped within bone or in the gingival tissue (2-4). OCs can be classified into inflammatory or developmental cysts according to their pathogenesis (4).

Commonly, OCs exhibit slow growth and a tendency towards expansion. However, these lesions can reach a marked size if they are not diagnosed in time and treated appropriately (4). In addition, some OCs such as odontogenic keratocysts and botryoid odontogenic cysts present a locally aggressive behavior and are prone to recurrence $(5,6)$. Therefore, the correct diagnosis of these lesions is essential for correct surgical treatment and the institution of adequate follow-up (5).

Since a number of cystic lesions of the jaws share similar clinical and radiographic features (2), the diagnosis of OCs usually requires a detailed analysis of clinical, radiographic, and histopathologic findings. Despite some sampling bias, oral pathology diagnostic services currently represent the most reliable source of information regarding the relative frequency and clinical-pathologic features of OCs $(4,7)$.

Despite the large number of studies on OCs in the literature, information regarding the demographic profile of these lesions in different populations is scarce, especially in the case of the Latin American population $(3-5,8)$. Thus, the objective of the present study was to determine the distribution of odontogenic cysts diagnosed histologically over a period of 38 years in a Brazilian population according to age, gender and site affected.

\section{Material and Methods}

After approval by the Ethics Committee of the Federal University of Rio Grande do Norte (UFRN), case records from patients with OC diagnosed between 1970 and 2007 were retrieved from the files of the Oral Pathology Service at UFRN, Natal, Brazil. Data regarding age, gender and anatomic location of all cases were compiled from the clinical data sent together with the biopsy records. Race was not considered in this study because the Brazilian population consists of an extensive admixture of Amerindians, Europeans, and Africans (9). Thus, there is no race categorization that would reflect the true ethnic distribution.

Hematoxylin/eosin-stained slides of OCs or nonspecific cyst diagnoses were selected and re-evaluated by three pathologists according to the 1992 World Health Organization (WHO) histologic classification (10). The histologic criteria for the diagnosis of calcifying odontogenic cysts were those proposed by Buchner (11). Orthokeratinized odontogenic cysts were diagnosed according to Wright (12). The number of specimens, male:female ratio, anatomic site, and mean age and standard deviation were determined for each case. These data were also analyzed regarding the distribution of OCs in the pediatric (16 years or younger) and adult population (17 years or older). The Microsoft ExcelTM software was used for data analysis and construction of the graphs.

\section{Results}

Among the 9216 oral biopsies retrieved from the archives of the Oral Pathology Service at UFRN comprising a period of 38 years, 1019 (11.0\%) presented criteria of OCs. Of these, $570(55.9 \%)$ were observed in women and $449(44.1 \%)$ in men, with a male:female ratio of $0.78: 1$. The mean age was 31.0 years (range, newborn to 86 years), with $68.3 \%$ of the cases being diagnosed between the second and fourth decades of life. The overall frequency of OCs in all age groups over the 38-year period is shown in table 1 . Table 2 shows the frequency of OCs in the pediatric and adult population.

Information regarding the anatomic site involved was available in 927 cases $(91.0 \%)$, with 499 cases $(53.8 \%)$ affecting the maxilla and 428 (46.2\%) occurring in the mandible. The distribution of OCs according to anatomic site is shown in table 3 . Radicular cysts, dentigerous cysts, and odontogenic keratocysts were the most frequent lesions, accounting for $87.9 \%$ of all OCs stored in the archives of our service.

Radicular cysts were the most common diagnosis $(61.4 \%)$, with a male:female ratio of $0.61: 1$. Most cases were located in the maxilla (63.05\%). In the mandible, $81.04 \%$ of the lesions affected the posterior region. Radicular cysts were the most frequent type of cyst in adults $(66.5 \%)$ and the second most common OC in the pediatric population (43.1\%). The mean age at diagnosis was 31.5 years, with a peak incidence between the second and fourth decades of life (Fig. 1).

Dentigerous cysts were the second most common diagnosis $(20.1 \%)$, with a male:female ratio of $1.44: 1$. The posterior region of the mandible was the most affected site $(46.3 \%)$, followed by the anterior region of the maxilla $(27.8 \%)$. The mean age at diagnosis was 21.3 years, with a peak incidence in the second decade of life (Fig. 2). Dentigerous cysts were the most common OC in the pediatric population (48.7\%) and the second most frequent in the adult population (13.0\%).

Odontogenic keratocysts were the third most prevalent type of OC (6.4\%). The mean age at diagnosis was 37.8 years, with a peak incidence between the third and fourth decades of life (Fig. 3) and a male:female ratio of $0.8: 1$. The posterior region of the mandible was the site most frequently affected (65.6\%). Among the 61 cases for which information about age was available, $55(90.1 \%)$ were diagnosed in adults and only $6(9.9 \%)$ were observed in pediatric patients.

Fifty cases of residual cysts were identified, accoun- 
Table 1. Rank order distribution of odontogenic cysts by frequency.

\begin{tabular}{|l|c|c|c|c|c|c|c|}
\hline \multicolumn{1}{|c|}{ CYSTS } & $\mathbf{n}$ & $\mathbf{\%}$ & $\mathbf{M} *$ & $\mathbf{F}^{*}$ & Ratio M:F & $\begin{array}{c}\text { Age range } \\
\text { (years) }\end{array}$ & $\begin{array}{c}\text { Mean age ( } \pm \text { DP) } \\
\text { (years) }\end{array}$ \\
\hline Radicular cyst & 626 & 61.4 & 238 & 388 & 0.61 & $4-86$ & $31.5(15.1)$ \\
\hline Dentigerous cyst & 205 & 20.1 & 121 & 84 & 1.44 & $4-83$ & $21.3(14.9)$ \\
\hline Odontogenic keratocyst & 65 & 6.4 & 29 & 36 & 0.8 & $2-85$ & $37.8(17.7)$ \\
\hline Residual cyst & 50 & 4.9 & 27 & 23 & 1.17 & $16-78$ & $44.5(17.3)$ \\
\hline Calcifying odontogenic cyst & 29 & 2.8 & 11 & 18 & 0.61 & $11-85$ & $45.7(22.5)$ \\
\hline Paradental cyst & 17 & 1.7 & 3 & 14 & 0.21 & $19-68$ & $28.3(12.4)$ \\
\hline Lateral periodontal cyst & 12 & 1.2 & 7 & 5 & 1.4 & $13-60$ & $37.0(13.0)$ \\
\hline Botryoid odontogenic cyst & 5 & 0.5 & 5 & 0 & $\infty$ & $34-83$ & $65.2(18.9)$ \\
\hline Orthokeratinized odontogenic cyst & 4 & 0.4 & 4 & 0 & $\infty$ & $25-58$ & $39.7(15.1)$ \\
\hline Eruption cyst & 3 & 0.3 & 3 & 0 & $\infty$ & $5-13$ & $8.0(4.3)$ \\
\hline Glandular odontogenic cyst & 2 & 0.2 & 1 & 1 & 1.0 & $45-64$ & $54.5(13.4)$ \\
\hline Gingival cyst of infant & 1 & 0.1 & 0 & 1 & 0 & 0,03 & $0.03(0.0)$ \\
\hline TOTAL & 1019 & 100 & 449 & 570 & 0.78 & $0-86$ & $31.0(16.9)$ \\
\hline
\end{tabular}

*M: male, F: female.

Table 2. Rank order distribution of odontogenic cysts by frequency in pediatric and adult populations.

\begin{tabular}{|c|c|c|c|c|c|c|c|}
\hline \multicolumn{8}{|c|}{ PEDIATRIC POPULATION } \\
\hline CYSTS & $\mathbf{n}$ & $\%$ & $\mathbf{M} *$ & $\mathbf{F}^{*}$ & $\begin{array}{l}\text { Ratio } \\
\text { M:F }\end{array}$ & $\begin{array}{l}\text { Age range } \\
\text { (years) }\end{array}$ & $\begin{array}{c}\text { Mean age } \\
( \pm \text { DP) (years) }\end{array}$ \\
\hline Dentigerous cyst & 96 & 48.7 & 67 & 29 & 2.31 & $4-16$ & $12.9(3.2)$ \\
\hline Radicular cyst & 85 & 43.1 & 36 & 49 & 0.73 & $4-16$ & $12.8(3.2)$ \\
\hline Odontogenic keratocyst & 6 & 3.0 & 6 & 0 & $\infty$ & $2-15$ & $11.3(4.8)$ \\
\hline Calcifying odontogenic cyst & 4 & 2.0 & 2 & 2 & 1.0 & $11-15$ & $13.3(2.0)$ \\
\hline Eruption cyst & 3 & 1.5 & 3 & 0 & $\infty$ & $5-13$ & $8.0(4.3)$ \\
\hline Residual cyst & 1 & 0.5 & 0 & 1 & 0 & 16 & $16(0.0)$ \\
\hline Lateral periodontal cyst & 1 & 0.5 & 0 & 1 & 0 & 13 & $13(0.0)$ \\
\hline Gingival cyst of infant & 1 & 0.5 & 0 & 1 & 0 & 0,03 & $0.03(0.0)$ \\
\hline TOTAL & 197 & 100 & 114 & 83 & 1.37 & $0-16$ & $11.6(3.6)$ \\
\hline \multicolumn{8}{|c|}{ ADULT POPULATION } \\
\hline CYSTS & $\mathbf{n}$ & $\%$ & M* & $F^{*}$ & $\begin{array}{l}\text { Ratio } \\
\text { M:F }\end{array}$ & $\begin{array}{l}\text { Age range } \\
\text { (years) }\end{array}$ & $\begin{array}{c}\text { Mean age } \\
( \pm \text { DP) (years) }\end{array}$ \\
\hline Radicular cyst & 521 & 66.5 & 196 & 325 & 0.6 & $17-86$ & $34.5(14.1)$ \\
\hline Dentigerous cyst & 102 & 13.0 & 51 & 51 & 1.0 & $17-83$ & $31.5(14.3)$ \\
\hline Odontogenic keratocyst & 55 & 7.0 & 23 & 32 & 0.71 & $18-85$ & $40.7(16.1)$ \\
\hline Residual cyst & 46 & 5.9 & 25 & 21 & 1.19 & $19-78$ & $45.1(16.9)$ \\
\hline Calcifying odontogenic cyst & 23 & 2.9 & 7 & 16 & 0.43 & $19-85$ & $51.2(19.6)$ \\
\hline Paradental cyst & 15 & 1.9 & 3 & 12 & 0.25 & $19-68$ & $28.3(12.4)$ \\
\hline Lateral periodontal cyst & 11 & 1.4 & 7 & 4 & 1.75 & $21-60$ & $39.1(11.1)$ \\
\hline Botryoid odontogenic cyst & 5 & 0.6 & 5 & 0 & $\infty$ & $34-83$ & $65.2(18.9)$ \\
\hline Orthokeratinized odontogenic cyst & 4 & 0.5 & 4 & 0 & $\infty$ & $25-58$ & $39.7(15.1)$ \\
\hline Glandular odontogenic cyst & 2 & 0.3 & 1 & 1 & 1.0 & $45-64$ & $54.5(13.4)$ \\
\hline TOTAL & 784 & 100 & 322 & 462 & 0.69 & $17-86$ & $35.9(15.3)$ \\
\hline
\end{tabular}

*M: male, F: female. 
Table 3. Distribution of odontogenic cysts according to anatomic site.

\begin{tabular}{|c|c|c|c|c|c|c|c|c|}
\hline \multirow[b]{2}{*}{ CYSTS } & \multicolumn{3}{|c|}{ MAXILLA n (\%) } & \multicolumn{3}{|c|}{ MANDIBLE n (\%) } & \multirow[b]{2}{*}{$\begin{array}{c}\text { Not } \\
\text { specified }\end{array}$} & \multirow[b]{2}{*}{ Total } \\
\hline & Anterior & Posterior & $\begin{array}{c}\text { Anterior } \\
\text { and } \\
\text { Posterior }\end{array}$ & Anterior & Posterior & $\begin{array}{l}\text { Anterior } \\
\text { and } \\
\text { Posterior }\end{array}$ & & \\
\hline Radicular cyst & $205(32.7)$ & $148(23.6)$ & $7(1.1)$ & $34(5.4)$ & $171(27.3)$ & $6(1.0)$ & $55(8.8)$ & $626(100.0)$ \\
\hline Dentigerous cyst & $57(27.8)$ & $19(9.3)$ & $5(2.4)$ & $10(4.9)$ & $95(46.3)$ & $3(1.5)$ & $16(7.8)$ & $205(100.0)$ \\
\hline $\begin{array}{l}\text { Odontogenic } \\
\text { keratocyst }\end{array}$ & $7(10.8)$ & $2(3.1)$ & - & $5(7.7)$ & $40(61.5)$ & $7(10.8)$ & $4(6.2)$ & $65(100.0)$ \\
\hline Residual cyst & $14(28.0)$ & $11(22.0)$ & $2(4.0)$ & $6(12.0)$ & $10(20.0)$ & $2(4.0)$ & $5(10.0)$ & $50(100.0)$ \\
\hline $\begin{array}{l}\text { Calcifying } \\
\text { odontogenic cyst }\end{array}$ & $3(10.3)$ & $5(17.2)$ & $3(10.3)$ & $3(10.3)$ & $7(24.1)$ & $1(3.4)$ & $7(24.1)$ & $29(100.0)$ \\
\hline Paradental cyst & - & $1(5.9)$ & - & - & $15(88.2)$ & - & $1(5.9)$ & $17(100.0)$ \\
\hline $\begin{array}{l}\text { Lateral } \\
\text { periodontal cyst }\end{array}$ & $3(25.0)$ & $2(16.7)$ & - & $1(8.3)$ & $5(41.7)$ & - & $1(8.3)$ & $12(100.0)$ \\
\hline $\begin{array}{l}\text { Botryoid } \\
\text { odontogenic cyst }\end{array}$ & - & - & - & $1(20.0)$ & $2(40.0)$ & - & $2(40.0)$ & $5(100.0)$ \\
\hline $\begin{array}{l}\text { Orthokeratinized } \\
\text { odontogenic cyst }\end{array}$ & $2(50.0)$ & - & - & - & $2(50.0)$ & - & - & $4(100.0)$ \\
\hline Eruption cyst & $1(33.3)$ & - & - & - & $1(33.3)$ & - & $1(33.3)$ & $3(100.0)$ \\
\hline $\begin{array}{l}\text { Glandular } \\
\text { odontogenic cyst }\end{array}$ & - & - & $1(50.0)$ & $1(50.0)$ & - & - & - & $2(100.0)$ \\
\hline $\begin{array}{l}\text { Gingival cyst of } \\
\text { infant }\end{array}$ & $1(100.0)$ & - & - & - & - & - & - & $1(100.0)$ \\
\hline TOTAL & $293(28.8)$ & $188(18.4)$ & $18(1.8)$ & $61(6.0)$ & $348(34.2)$ & $19(1.9)$ & $92(9.0)$ & $\begin{array}{c}1019 \\
(100.0)\end{array}$ \\
\hline
\end{tabular}

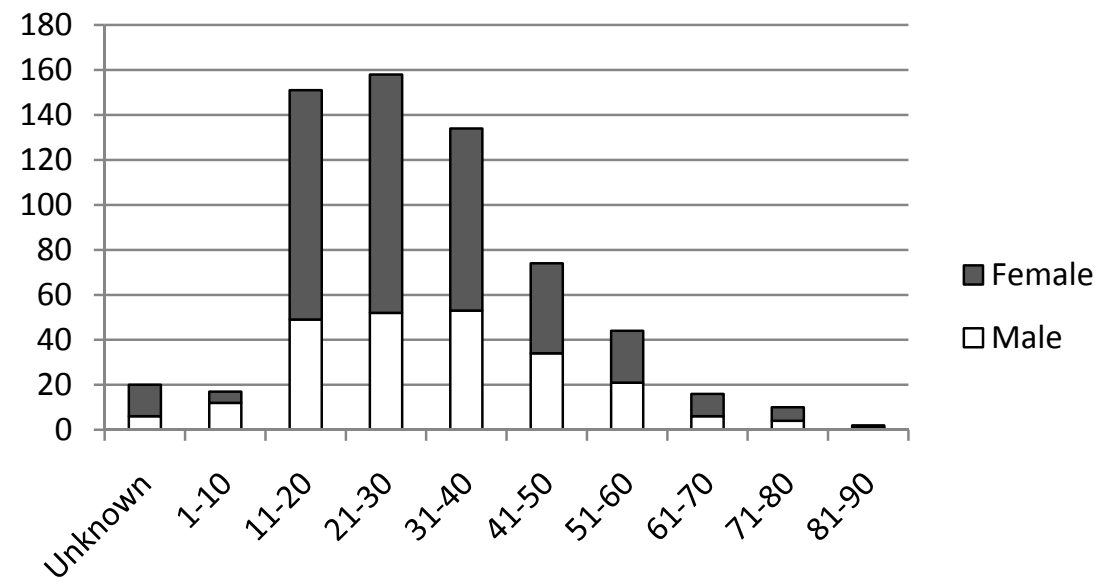

Fig. 1. Distribution of radicular cysts according to age and gender. 


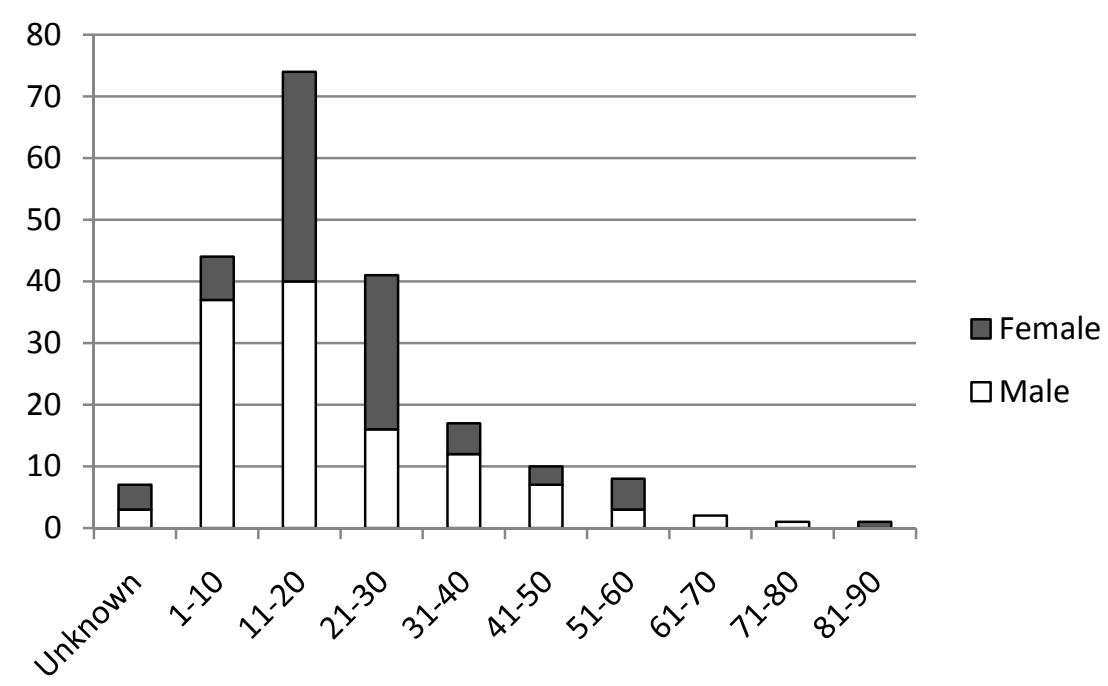

Fig. 2. Distribution of dentigerous cysts according to age and gender.

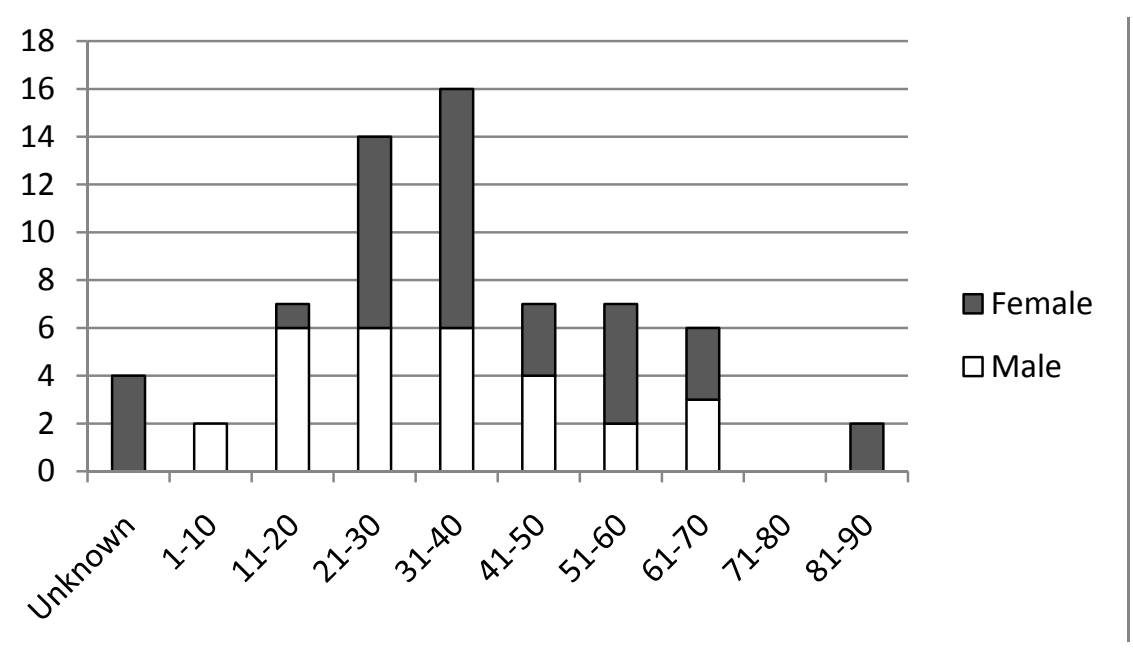

Fig. 3. Distribution of odontogenic keratocysts according to age and gender.

ting for $4.9 \%$ of all OCs. These lesions were commonly observed in men, with a male:female ratio of $1.17: 1$. The mean age at diagnosis was 44.5 years, with only one case being diagnosed in a child. Information about the anatomic site was available in 45 cases. Twenty-seven $(60.0 \%)$ lesions involved the maxilla and 18 (40.0\%) affected the mandible. The anterior region of the maxilla was the single most common location of residual cysts (31.1\%).

Calcifying odontogenic cysts and paradental cysts accounted for $2.8 \%$ and $1.7 \%$ of all OCs, respectively. Most cases of calcifying odontogenic cysts were observed in adults $(85.2 \%)$, with a mean age of 45.7 years. All paradental cysts were diagnosed in adults, with a mean age of 28.3 years. Among the 22 cases of calcifying odontogenic cysts for which information about the anatomic site was available, $11(50.0 \%)$ affected the maxilla and $11(50.0 \%)$ the mandible. With respect to paradental cysts, the posterior region of the mandible was the single site most frequently involved by these lesions $(88.2 \%)$.

The remaining 27 OCs comprised 12 lateral periodontal cysts $(1.2 \%), 5$ botryoid odontogenic cysts $(0.5 \%), 4$ orthokeratinized odontogenic cysts $(0.4 \%), 3$ eruption cysts $(0.3 \%), 2$ glandular odontogenic cysts $(0.2 \%)$, and one gingival cyst in an infant $(0.1 \%)$. Most cases of lateral periodontal cysts $(91.6 \%)$ were diagnosed in adults, with a mean age of 37.0 years. Regarding anatomic site, 
the posterior region of the mandible (45.5\%) was the single most common location of periodontal lateral cysts. Botryoid odontogenic cysts and orthokeratinized odontogenic cysts affected only adults, with a mean age of 65.2 years and 39.7 years, respectively. Eruption cysts were only observed in children, with a mean age at diagnosis of 8.0 years. Cases of gingival cyst of the adult were not identified in the present study.

\section{Discussion}

OCs are one of the most common lesions affecting the jaws and many of these cysts share similar clinical and radiographic features (2). Therefore, the diagnosis of OCs should be based on careful examination of clinical, radiographic, and histopathologic features. Most of the information regarding the prevalence of OCs comes from oral pathology diagnostic services and, despite some sampling bias, these services represent a reliable source of information regarding the relative frequency and clinical-pathologic features of OCs $(4,7)$.

Nevertheless, in the present study some records sent together with the biopsy material were incomplete. This finding, which is even observed for records stored only over the last 5 years, highlights the fact that some practitioners are careless when filling out clinical charts, a fact impairing the histopathologic diagnosis and, consequently, the execution of retrospective studies. In order to guarantee the most reliable epidemiologic profile of OCs in our population, unclassified cysts due to insufficient clinical data were excluded from this study.

The 1.019 cases of OCs identified in the present study accounted for $11.0 \%$ of all specimens stored in the archives of the Oral Pathology Service at UFRN. Similar results have been reported in previous studies invol-ving populations from Brazil (3), Chile (4), Sicilia (13), and the United Kingdom (2). Studies involving Mexican populations have shown lower frequencies of OCs ranging from $7.8 \%$ to $8.4 \%(6,7)$. Nevertheless, OCs may account for $0.8 \%$ to $45.9 \%$ of all specimens submitted to histopathologic analysis at oral pathology services $(14,15)$. This wide range in the frequency of OCs pro-bably reflects differences in referral practice or biased data due to the analysis of specific age groups (2).

The discrete predominance of females in our series (55.9\%) disagrees with other study conducted on Brazilian populations, which reported a relatively similar distribution of OCs in both genders (3). It should be emphasized that the Oral Pathology Service of UFRN is a referral center in oral and maxillofacial pathology located in the northeastern region of Brazil, whereas previous study involving Brazilian populations have been performed at a referral center located in the southeastern (3) region of Brazil. Studies conducted in other countries also reported a male predominance, with frequencies ranging from $52.5 \%$ to $65.0 \%(2,5,7,8,13)$.
The discrete predominance of females observed in the present study might represent a peculiar characteristic of the population from the northeastern region of Brazil. Further studies should be performed at other referral centers in this region in order to confirm this hypothesis.

With respect to anatomic location, most OCs affected the mandible, particularly the posterior region (34.7\%), followed by the anterior region of the maxilla (26.2\%). Coherently, these regions have been reported as the most common location of odontogenic cystic lesions in other studies $(2,16)$. In contrast, a study conducted in Lithuania found a higher frequency of OCs in the maxi1la, with a proportion of 1.5:1 (17). It should be emphasized that the latter study only evaluated radicular and dentigerous cysts, a fact that might explain the differences in the results.

Our results showed a higher prevalence of inflammatory cysts $(68.0 \%)$. A higher proportion of inflammatory cysts has also been observed in other studies involving different populations, with frequencies ranging from $58.2 \%$ to $74.3 \%(2,4,8,18,19)$. On the other hand, studies involving populations from Mexico $(5,13)$ demonstrated a higher frequency of developmental cysts. It is possible that the socioeconomic conditions of the population might influence the relative frequency of inflammatory and developmental OCs. Mosqueda-Taylor et al. (7) observed a higher frequency of developmental OCs in patients seen at a private clinic and a higher proportion of inflammatory OCs in patients attended at a public health service.

In the present study, the most common OCs were radicular cysts, dentigerous cysts, and odontogenic keratocysts. These lesions accounted for $87.9 \%$ of all OCs stored in the archives of our service. Similar results have been reported in studies involving populations from Brazil (3) and from other countries $(2,4,5,8)$.

Radicular cysts are the most frequent type of OC, accounting for $39.9 \%$ to $86.2 \%$ of all OCs stored in the archives of oral pathology services $(2,4,5,7,8,15,17-19)$. In agreement with other studies $(4,5,18,19)$, our results showed an increase in the incidence of radicular cysts between the second and fourth decades of life. In contrast, studies involving populations from the United Kingdom (2) and Brazil (3) have shown a peak incidence between the third and fourth decades of life.

As observed in the present investigation and in other studies $(2-4,5,18,19)$, the anterior region of the maxilla is the most common location of radicular cysts. According to Ochsenius et al. (4) esthetic factors may cause individuals to conserve these teeth, and these patients are therefore more prone to long-term chronic inflammatory processes in the absence of adequate endodontic treatment. In agreement with other studies (2,8, 17-19), in our series radicular cysts were more prevalent among 
males. In contrast, a study involving other Brazilian population (3) has shown a slightly higher prevalence among females, in agreement with other investigations conducted in Latin American countries $(4,5,7)$. The male predominance of radicular cysts might be related to the fact that men are more likely to neglect their oral hygiene and are more prone to trauma to the maxillary anterior teeth (8).

Dentigerous cysts have been described as the second most common OC, with frequencies ranging from $11.4 \%$ to $33.0 \%(1,3,4,8,10,11)$. Most cases are diagnosed in men $(2,3,13)$. The posterior region of the mandible is the site most frequently affected by these lesions, followed by the anterior region of the maxilla (2). Similar findings were observed in the present study. According to Jones et al. (2), the high frequency of dentigerous cysts at these sites is not a surprising finding since the lower third molars and upper canines are the teeth most commonly impacted. Most cases of dentigerous cysts are diagnosed between the first and second decades of life $(4,5,18,19)$, a fact also observed in the present study. However, Jones et al. (2) reported a peak incidence between the fifth and sixth decades. In addition, dentigerous cysts were identified as the most common OC in the pediatric population in the present investigation and in the study of Ochsenius et al. (4), whereas Jones et al. (2) identified radicular cysts as the most frequent $\mathrm{OC}$ in children $(43.6 \%)$. Whether this peak incidence of dentigerous cysts in older age groups is a particular characteristic of this European population is still a matter of discussion.

Odontogenic keratocysts have been described as the third most common type of $\mathrm{OC}$, with frequencies ranging from $1.3 \%$ to $21.5 \%(1,3,4,5,7,8,13)$, in agreement with the present findings. Most cases of odontogenic keratocysts are diagnosed in men between the second and third decades of life $(2-4,5,7,8)$. In contrast, a study conducted on a population from Turkey demonstrated a higher frequency of these lesions in women (19). Our results also showed a predominance of odontogenic keratocysts among males, but a peak incidence of these lesions was observed between the third and fourth decades of life. The posterior region of the mandible is the single most common location of odontogenic keratocysts $(3-5,7,8)$. In agreement with previous reports $(2,3)$, in the present study odontogenic keratocysts were the third most frequent type of $\mathrm{OC}$ in the pediatric population. However, in this series the frequency of these lesions among children $(3.0 \%)$ was lower than that reported in the literature $(2,3)$. Studies performed in Europe (2) and Chile (3) showed that odontogenic keratocysts accounted for $18.1 \%$ and $23.3 \%$ of all OCs diagnosed in pediatric populations, respectively.

The clinical and histopathologic features of calcifying odontogenic cysts have generated disagreement and confusion regarding their classification and terminology (20). On the basis of the new WHO concept, calcifying odontogenic cysts not only contain a neoplasm but also a cyst (3). In order to permit comparison with previous studies, the present cases of calcifying odontogenic cysts were evaluated according to the classification of Buchner (11) and only cases belonging to the cystic variant were included in the study. In the present study, the frequency of calcifying odontogenic cysts $(2.8 \%)$ was higher than that reported in previous studies in which these lesions accounted for $1.0 \%$ or less of all OCs $(2,3)$. In contrast to other reports $(2,20)$, in the present series most cases were diagnosed in women. Regarding anatomic location, our results showed a similar distribution in the mandible and maxilla. However, a previous study conducted on another Brazilian population demonstrated a higher frequency of calcifying odontogenic cysts in the mandible (3).

\section{Conclusions}

In conclusion, the present results show a similar frequency of OCs in the Brazilian population studied here and other populations around the world, with inflammatory cysts being identified as the most frequent OC. Radicular cysts, dentigerous cysts and odontogenic keratocysts are the most common OCs, accounting for $87.9 \%$ of all OCs. Further studies including large series of OCs should be performed in different regions of the world in order to determine the global epidemiologic profile of these lesions.

\section{References}

1. Daley TD, Wysocki GP, Pringle GA. Relative incidence of odontogenic tumors and oral and jaw cysts in a Canadian population. Oral Surg Oral Med Oral Pathol. 1994 ;77:276-80.

2. Jones AV, Craig GT, Franklin CD. Range and demographics of odontogenic cysts diagnosed in a UK population over a 30 -year period. J Oral Pathol Med. 2006;35:500-7.

3. Grossmann SM, Machado VC, Xavier GM, Moura MD, Gomez RS, Aguiar MC, et al. Demographic profile of odontogenic and selected nonodontogenic cysts in a Brazilian population. Oral Surg Oral Med Oral Pathol Oral Radiol Endod. 2007;104:e35-41.

4. Ochsenius G, Escobar E, Godoy L, Peñafiel C. Odontogenic cysts: analysis of 2,944 cases in Chile. Med Oral Patol Oral Cir Bucal. 2007;12:E85-91.

5. Ledesma-Montes C, Hernández-Guerrero JC, Garcés-Ortíz M. Clinico-pathologic study of odontogenic cysts in a Mexican sample population. Arch Med Res. 2000;31:373-6.

6. Kaplan I, Gal G, Anavi Y, Manor R, Calderon S. Glandular odontogenic cyst: treatment and recurrence. J Oral Maxillofac Surg. 2005;63:435-41.

7. Mosqueda-Taylor A, Irigoyen-Camacho ME, Diaz-Franco MA, Torres-Tejero MA. Odontogenic cysts. Analysis of 856 cases. Med Oral. 2002;7:89-96.

8. Meningaud JP, Oprean N, Pitak-Arnnop P, Bertrand JC. Odontogenic cysts: a clinical study of 695 cases. J Oral Sci. 2006;48:59-62.

9. Parra FC, Amado RC, Lambertucci JR, Rocha J, Antunes CM, Pena SD. Color and genomic ancestry in Brazilians. Proc Natl Acad Sci U S A. 2003;100:177-82.

10. Kramer IR, Pindborg JJ, Shear M. The WHO Histological Typing 
of Odontogenic Tumours. A commentary on the Second Edition. Cancer. 1992;70:2988-94.

11. Buchner A. The central (intraosseous) calcifying odontogenic cyst: an analysis of 215 cases. J Oral Maxillofac Surg. 1991;49:330-9.

12. Wright JM. The odontogenic keratocyst: orthokeratinized variant. Oral Surg Oral Med Oral Pathol. 1981;51:609-18.

13. Tortorici S, Amodio E, Massenti MF, Buzzanca ML, Burruano F, Vitale F. Prevalence and distribution of odontogenic cysts in Sicily: 1986-2005. J Oral Sci. 2008;50:15-8.

14. Skinner RL, Davenport WD Jr, Weir JC, Carr RF. A survey of biopsied oral lesions in pediatric dental patients. Pediatr Dent. 1986;8:163-7.

15. Gültelkin SE, Tokman B, Türkseven MR. A review of paediatric oral biopsies in Turkey. Int Dent J. 2003;53:26-32.

16. Regezi JA. Odontogenic cysts, odontogenic tumors, fibroosseous, and giant cell lesions of the jaws. Mod Pathol. 2002;15:331-41.

17. Varinauskas V, Gervickas A, Kavoliūniene O. Analysis of odontogenic cysts of the jaws. Medicina (Kaunas). 2006;42:201-7.

18. Bataineh AB, Rawashdeh MA, Al Qudah MA. The prevalence of inflammatory and developmental odontogenic cysts in a Jordanian population: a clinicopathologic study. Quintessence Int. 2004;35:815-9.

19. Koseoglu BG, Atalay B, Erdem MA. Odontogenic cysts: a clinical study of 90 cases. J Oral Sci. 2004;46:253-7.

20. Fregnani ER, Pires FR, Quezada RD, Shih IeM, Vargas PA, de Almeida OP. Calcifying odontogenic cyst: clinicopathological features and immunohistochemical profile of 10 cases. J Oral Pathol Med. 2003;32:163-70. 